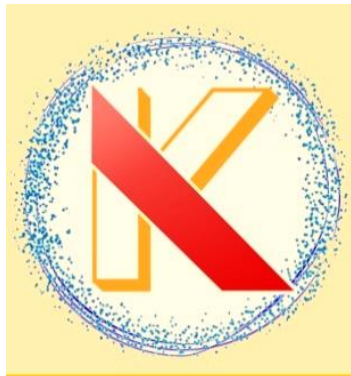

Contents list available at KOVALEN website

KOVALEN: Jurnal Riset Kimia

Journal homepage: https://bestjournal.untad.ac.id/index.php/kovalen

\title{
Sintesis Metil Ester Asam Lemak dari Biji Alpukat (Parsea americana Mill) Menggunakan Polimer Penyangga Katalis Berbahan Dasar Eugenol
}

\section{[Synthesis of Fatty Acid Methyl Ester from Avocado Seeds (Parsea americana Mill) using Polymer Support Catalyst Based on Eugenol]}

\author{
Sumarni*, Erwin Abdul Rahim, Ni Ketut Sumarni, Ruslan, Hardi Ys., Moh. Mirzan \\ Jurusan Kimia, Fakultas Matematika dan Ilmu Pengetahuan Alam, Universitas Tadulako, \\ Jl. Soekarno-Hatta Km. 9, Kampus Bumi Tadulako, Palu, Indonesia \\ *Corresponding author: marniusman18@gmail.com
}

\begin{abstract}
Research on the manufacture of methyl esters from avocado seeds (Parsea americana Mill) with eugenol-based catalysts has been conducted. The aim is to determine the catalyst concentration used to produce methyl esters with the highest rendement and determine the composition of fatty acid methyl ester in avocado seeds. This study was used variations in concentrations of $0.25 \%, 1 \%, 1.75 \%, 2.25 \%$, and $3 \%$. The results of this study showed that the best concentration is $2.25 \%$ with the calculation of the results of $24.8 \%$ methyl esters in avocado seeds, namely lignoceric and octadecenoic acid methyl ester.
\end{abstract}

Keywords: Avocado seeds, fatty acid methyl esters

ABSTRAK. Telah dilakukan penelitian tentang sintesis metil ester asam lemak dari biji alpukat (Parsea americana Mill) menggunakan katalis berbahan dasar eugenol. Tujuan penelitian adalah mengetahui konsentrasi katalis untuk menghasilkan metil ester asam lemak dengan rendemen tertinggi dan mengetahui komposisi metil ester asam lemak pada biji alpukat. Pada penelitian ini digunakan variasi konsentrasi konsentrasi katalis yaitu $0,25 \% ; 1 \%$; 1,75\%; 2,25\%; dan $3 \%$. Hasil penelitian ini menunjukan konsentrasi terbaik yaitu 2,25 \% dengan perhitungan hasil metil ester $24,8 \%$ dan metil ester pada biji alpukat yaitu metil lignoserat dan metil-11-oktadekenoat.

Kata kunci : Biji alpukat, metil ester asam lemak

Riwayat artikel: Diterima 2 Juli 2019, Disetujui 29 November 2020

Cara sitasi: Sumarni., Erwin, A R., Sumarni, N K., Ruslan., Ys, H., \& Mirzan, M. (2020). Sintesis Metil Ester Asam Lemak dari Biji Alpukat (Parsea americana Mill) Menggunakan Polimer Penyangga Katalis Berbahan Dasar Eugenol. KOVALEN: Jurnal Riset Kimia, 6(3): 206-211.

DOI: https://doi.org/10.22487/kovalen.2020.v6.i3.13053

\section{LATAR BELAKANG}

Alpukat (Persea americana Mill) termasuk jenis tanaman tropis khas Indonesia dan meimiliki kandungan antioksidan yang cukup tinggi (Halimah et al., 2014). Pada sisi lain, biji alpukat belum dimanfaatkan dengan maksimal atau hanya terbuang sebagai limbah. Hasil penelitian fitokimia, ekstrak biji alpukat menunjukkan bahwa biji alpukat mengandung banyak senyawa metabolit sekunder (Zuhrotun, 2007). Selain senyawa metabolit sekunder, biji alpukat juga mengandung minyak yang cukup 
tinggi, yaitu $32,8 \%$ sehingga biji alpukat dapat dijadikan sebagai sumber minyak nabati (Marlina \& Pratama, 2018). Minyak biji alpukat dapat diperoleh dengan metode ekstraksi maupun metode pengepresan. Komponen asam lemak utama dalam minyak biji alpukat meliputi asam oleat $71,7 \%$; asam linoleat $13,1 \%$, asam palmitat $6 \%$, dan asam asam stearat 1,5\% (Pramudono, 2004 dalam Risnoyatiningsih, 2010). Merujuk dari komponen tersebut, maka minyak biji alpokat potensial untuk dijadikan sebagai bahan dasar pembuatan biodiesel.

Kebutuhan bahan bakar diesel semakin bertambah seiring dengan bertambahnya kendaraan dan industri di Indonesia. Hal inilah yang akan mengakibatkan impor solar semakin meningkat. Salah satu sumber energi altenatif yang bisa digunakan sebagai bahan bakar diesel sebagai pengganti bahan bakar minyak konvensional yaitu minyak nabati. Minyak nabati dapat terurai secara biologis dan lebih sempurna (lebih dari 90\%). Bahan bakar diesel alternatif yang berasal dari minyak nabati umumnya dikenal sebagai biodiesel (Adhi, 2013). Bahan bakar biodiesel bersifat ramah lingkungan karena bersifat renewable atau gas emisi yang dihasilkan dalam bentuk COx akan lebih mudah diserap oleh tumbuhan $d n$ digunakan kembali pada proses fotosintesis. Proses ini akan menghasilkan siklus karbon sehingga akumulasi emisi $\mathrm{CO}_{2}$ penyebab efek rumah kaca tidak akan terjadi (Witjonarko \& Haryono, 2017).

Biodiesel biasa juga disebut sebagai senyawa metil ester, yaitu senyawa ester alkil yang berasal dari minyak nabati yang diperoleh melalui proses esterifikasi atau transesterifikasi dan mempunyai sifat fisika mendekati solar diesel. Reaksi transesterifikasi umumnya memerlukan katalis basa kuat seperti natrium hidroksida atau kalium hidroksida (Gerpen \& Shanks, 2005). Kadar asam lemak bebas yang terkandung dalam trigliserida dapat mempengaruhi dengan kuantitas dan kualitas metil ester yang dihasilkan (Arita et al., 2008).

Reaksi transesterifikasi dapaat pula menggunakan katalis asam kuat, seperti $\mathrm{HCl}$, $\mathrm{H}_{2} \mathrm{SO}_{4}$ dan asam kuat lainnya. Penambahan katalis sangat diperlukan untuk menghasilkan metil ester yang berfungsi mempercepat reaksi dengan menurunkan energi aktivasi reaksi namun tidak menggeser letak keseimbangan. Rekasi transesterifikasi dapat berjalan pada suhu sekitar $250^{\circ} \mathrm{C}$ jika tanpa penambahan katalis. Katalis yang biasa digunakan yaitu katalis asam dan basa. Katalis basa dapat bereaksi pada suhu kamar, sedangkan katalis asam dapat bereaksi pada suhu diatas $100^{\circ} \mathrm{C}$. Katalis asam akan lebih efisien digunakan untuk menghindari reaksi penyabunan dan waktu reaksi transesterifikasiini memerlukan katalis basa kuat seperti natrium hidroksida atau kalium hidroksida sehingga menghasilkan senyawa kimia baru yang disebut dengan metil ester asam lemak (Gerpen \& Shanks, 2005).

Transesterifikasi in situ merupakan salah satu metode yang diterapkan dalam proses pembuatan biodiesel/metil ester dengan melakukan ektraksi langsung pada sumber bahan baku yang mengandung minyak atau lemak. Pada proses in situ bahan baku yang digunakan adalah bahan padatan yang mengandung minyak atau lemak. Transesterifikasi in situ merupakan proses ektraksi minyak dan reaksi transeterifikasi dilangsungkan secara simultan dalam satu reaktor (Shiu et al., 2010). Mekanisme proses in situ dimulai dengan terjadinya proses kontak antara alkohol dan katalis asam atu basa. 
Selanjutnya alkohol masuk ke dalam sel dan menghancurkan bagian-bagian sel kemudian melarutkan minyak yang terkandung dalam bahan baku. Minyak yang telah terekstrak bereaksi dengan alkohol menghasilkan ester dengan bantuan katalis asam atau basa (Haas et al., 2004).

Katalis asam padat telah berkembang dilingkungan para peneliti sintesis dalam reaksi homogen dan heterogen. Salah satu katalis asam padat yaitu sintesis absolut asimetri yang baru hasil dari reaksi antara eugenol, propargilamid dan adisi metileugenol dengan campuran asam asetat dan $\mathrm{H}_{2} \mathrm{SO}_{4}$ yang hasilnya dapat diaplikasikan sebagai polimer penyangga katalis. Eugenol adalah senyawa yang diperoleh dari bahan alam dengan harga murah yang mengandung gugus fungsi fenolikhidrosil dan allil. Kelebihan lainnya dari katalis asam padat ini yaitu ramah terhadap lingkungan dengan bahan dasar eugenol yang dilarutkan dalam pelarut organik (Rahim, 2016).

\section{METODE PENELITIAN}

\section{Bahan dan Peralatan}

Bahan yang digunakan pada penelitian ini yaitu biji alpukat mentega (Parsea americana Mill) yang diperoleh dari penjual minuman jus alpukat di Kota Palu, metanol tekhnis, eugenol, aquades, asam sulfat (pekat), asam asetat glasial, n-heksan, $\mathrm{Na}_{2} \mathrm{SO}_{4}$ anhidrat, kertas saring, aluminium foil dan tisu.

Peralatan yang digunakan pada penelitian ini yaitu parutan, blender, termometer, hot plate,lemari asam, labu alas bulat, magnetik stirer, neraca analitik, corong buchner, corong pisah, rotary vacum evaporator, alat refluks, statif dan klem, GC-MS GC17A MSQP 5000
Shimadzu, dan alat-alat gelas lainnya yang biasa digunakan di Laboratorium.

\section{Prosedur Penelitian}

\section{Preparasi sampel}

Biji alpukat mentega dibersikan dari kulit ari yang menempel kemudian dicuci dengan air bersih, untuk memastikan biji alpukat bersih dari bahan pengotor lain, kemudian biji alpukat diparut dan dikeringkan dibawah sinar matahari selama 2-3 hari. Biji alpukat kering dihaluskan menggunakan blender dan diayak dengan ukuran 120 mesh (Risnoyatiningsih, 2010). Serbuk halus biji alpukat selanjutnya digunakan pada tahapan transesterifikasi in situ.

\section{Pembuatan katalis asam padat (Rahim et al., 2019)}

10 gram eugenol dimasukkan ke dalam gelas kimia $250 \mathrm{~mL}$ kemudian ditambahkan 2,5 $\mathrm{mL}$ larutan $\mathrm{H}_{2} \mathrm{SO}_{4}-\mathrm{CH}_{3} \mathrm{COOH} 4 \%$ dengan perbandingan 4:1 (monomer : katalis) sambil diaduk dengan pengaduk magnet. Penambahan katalis dilakukan dengan cara sedikit demi sedikit. Asam padat terbentuk ditandai dengan munculnya asap putih pekat dan polimer mengental atau mengeras di dinding gelas kimia

\section{Pembuatan metil ester secara in situ (trans) esterifikasi (Rahim et al., 2019)}

Timbang $25 \mathrm{gr}$ serbuk halus biji alpukat kemudian dimasukkan ke dalam labu alas bulat yang dilengkapi dengan pengaduk magnetik. Kemudian ditambahkan katalis dengan variasi konsentrasi katalis yaitu $0,25 \%, 1 \%, 1,75 \%$, $2,25 \%$ dan $3 \%$. Serta metanol dengan perbandingan 1:15 (sampel : metanol) $\mathrm{w} / \mathrm{v}$. Direfluks dengan suhu $60^{\circ} \mathrm{C}$ dengan waktu 120menit. Produk disaring dengan menggunakan corong buchner. Kemudian filtratnya di tambahkan akuades $30 \mathrm{~mL}$ dan $\mathrm{n}$ heksan $120 \mathrm{~mL}$. Campuran dimasukkan ke 
dalam corong pisah dan didiamkan selama 24 jam sampai terbentuk dua lapisan. Lapisan atas merupakan ester dan n-heksan dan lapisan bawah merupakan akuades dan katalisnya.Lapisan atas (ester dan n-heksan) dilewatkan dengan $\mathrm{Na}_{2} \mathrm{SO}_{4}$ anhidrat. Kemudian memisahkan ester dengan $\mathrm{n}$-heksan dengan cara dirotary dan diukur volumenya. Hasil yang diperoleh ditimbang dan dihitung rendemen metil ester dengan rumus:

Rendemen $=\frac{\text { Berat Metil Ester }}{\text { Berat sampel }} \times 100$

Komponen metil ester yang terbentuk dianalisis dengan menggunakan instrumentasi GC-MS.

\section{HASIL DAN PEMBAHASAN}

\section{Hasil Metil Ester Biji Alpukat Dengan Reaksi Transesterifikasi In Situ}

Pada penelitian ini peneliti menggunakan dua metode pembuatan metil ester yang bertujuan untuk melihat metode mana yang baik digunakan untuk pembuatan metil ester dari biji alpukat dengan katalis asam padat. Metode yang digunakan yaitu in situ.Hasil metil ester dari biji alpukat dengan metode in situ dengan variasi konsentrasi yaitu $0,25 \%, 1 \%, 1,75 \%$, $2,25 \%$, dan $3 \%$ dengan hasil rendemen yaitu $13,6 \%, 9,2 \%, 10 \%$, 24,8\%, dan $17,2 \%$, Pada konsentrasi katalis 2,25\% metil ester yang terbentuk cair dan dengan rendemen tertinggi yaitu 24,8 . Hal ini menunjukkan bahwa metode yang baik digunakan untuk pembuatan metil ester dari biji pala dengan katalis asam padat yaitu metodetransesterifikasi in situ.

\section{Pengaruh Konsentrasi Katalis Terhadap Rendemen Hasil}

Rendemen biodiesel cenderung semakin meningkat seiring meningkatnya jumlah katalis yang digunakan hingga pada penggunaan katalis 2,25\% terjadi penurunan (Gambar 1 ).

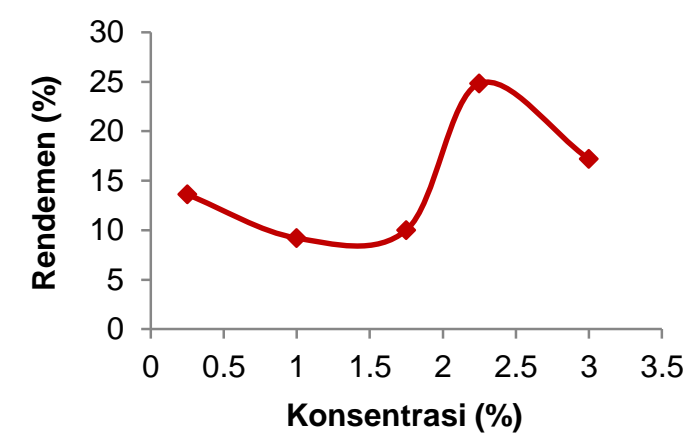

Gambar 1. Grafik pengaruh konsentrasi katalis terhadap rendemen hasil

Jumlah katalis asam yang terlalu tinggi atau berlebihan dapat memungkinkan terjadinya dehidrasi metanol menjadi alkena ataupun dimetil eter, sehingga dapat mempengaruhi kadar metil ester yang dihasilkan (Yuliani et al., 2008).

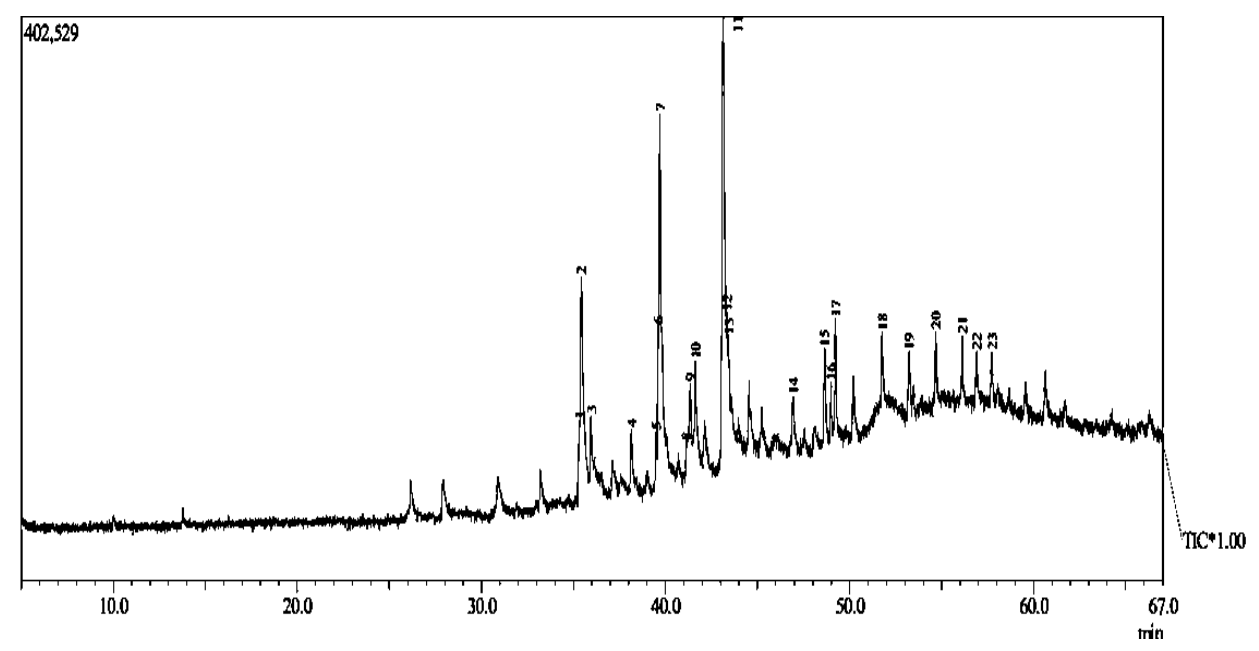

Gambar 2. Kromatogram metil ester biji alpukat 


\section{Hasil Analisis Metil Ester Menggunakan GC- MS}

Identifikasi metil ester dari minyak biji alpukat yang dihasilkan dari reaksi transesterifikasi in situ menggunakan instrumen GC-MS dilakukan untuk mengetahui kandungan senyawa yang ada dalam metil ester dari minyak biji alpukat. Adapun kromatogram metil ester dari minyak biji alpukat ditampilkan pada Gambar 2.

Dari Gambar 2 dan Tabel 1, telah diketahui bahwa metil ester dari biji alpukat yang dihasilkan mengandung senyawasenyawa metil ester, yaitu metil lignoserat 2,33\% dan metil oktadekenoat 3,32\%.

Tabel 1. Hasil analisis GC-MS

\begin{tabular}{cccc}
\hline Puncak & $\begin{array}{c}\text { Waktu } \\
\text { retensi, } \\
\text { tR } \\
\text { (menit) }\end{array}$ & $\begin{array}{c}\text { Luas } \\
\text { puncak } \\
(\%)\end{array}$ & Senyawa \\
\hline 4 & 38.149 & 2,33 & $\begin{array}{c}\text { Metil } \\
\text { lignoserat }\end{array}$ \\
10 & 41.631 & 3,32 & $\begin{array}{c}\text { Metil 11- } \\
\text { oktadekenoat }\end{array}$ \\
\hline
\end{tabular}

Menurut Risnoyatiningsih (2010) senyawa asam lemak dari biji alpukat yaitu oleat $(71,71 \%)$, linoleat $(13,13 \%)$, palmitat $(6,03 \%)$, miristat $(0,70 \%)$ dan stearat $(1,53 \%)$. Sepanjang pengetahuan penulis baru pertama kali dilaporkan bahwa biji alpukat mengandung metil ester yaitu metil 11-oktadekanoat (3,32\%) dan metil lignoserat (2,33\%).

Berdasarkan hal di atas, perbedaan dari hasil tersebut dipengaruhi oleh proses pembuatan metil ester dan katalis yang digunakan. Peneliti terdahulu mengekstrak minyak dari biji alpukat sedangkan pada penelitian ini tidak mengekstrak minyak dari biji alpukat dan menggunakan metode in situ sehingga masih banyak senyawa pengotor yang ikut dalam metil ester. Sementrara itu, pada penelitian ini menggunakan katalis asam padat dari hasil reaksi eugenol dan $\mathrm{H}_{2} \mathrm{SO}_{4}$ $\mathrm{CH}_{3} \mathrm{COOH}$.Katalis asam padat ini termasuk katalis selektif karena trigrliserida hanya membentuk ester asam lemak tertentu saja.

\section{KESIMPULAN}

Konsentrasi katalis asam padat yang baik digunakan dalam pembuatan metil ester dari minyak biji alpukat, yaitu $2,25 \%$ dengan rendemen hasil sebanyak $24,8 \%$. Komponen terbesar metil ester dari hasil transesterifikasi in situ adalah metil 11-oktadekenoat (3,32\%) dan metil lignoserat (2,33\%).

\section{DAFTAR PUSTAKA}

Adhi, W. (2013). Industri Minyak Sawit dan Biodiesel Sebagai Upaya Mengurangi Penggunaan Bahan Bakar Fosil [Skripsi]. IPB, Bogor.

Arita, S., Dara, M. B., \& Irawan, J. (2008). Pembuatan Metil Ester Asam Lemak Dari CPO Off Grade Dengan Metode Esterifikasi-Transesterifikasi. Jurnal Teknik Kimia, 15(2). http://jtk.unsri.ac.id/index.php/jtk/article/vi ew/52

Gerpen, J., \& Shanks, R. (2005). Colorado: Biodiesel Production Technology. National Renewable Energy Laboratory, Colorado.

Haas, M., Wagner, K., Marmer, W., \& Foglia, T. (2004). In situ alkaline transesterification: An effective method for the production of fatty acid esters from vegetable oils. Journal of Oil \& Fat Industries, 81(1): 8389. https://doi.org/10.1007/s11746-0040861-3

Halimah, A. D. N., Istiqomah -, \& Rohmah, S. S. (2014). Pengolahan Limbah Biji Alpukat Untuk Pembuatan Dodol Pati Sebagai Alternatif Pengobatan Ginjal. Jurnal IImiah Mahasiswa, 4(1): 32-37.

Marlina, L., \& Pratama, D. W. (2018). Pengambilan Minyak Biji Alpukat Dengan 
Metode Ekstraksi. Jurnal TEDC, 12(1): 31-37.

Rahim, E. A. (2016). Sintesis Absolut Asimetrik Baru. KOVALEN: Jurnal Riset Kimia, 2(1). http://jurnal.untad.ac.id/jurnal/index.php/k ovalen/article/view/6045

Rahim, E. A., Rihday, A., Bahri, S., \& Pusptasari, D. J. (2019). Transesterifikasi In Situ Biji Kelor (Moringa oleifera Lam) Menggunakan Polimer Berbahan Dasar Eugenol Sebagai Penyangga Katalis $\mathrm{H}_{2} \mathrm{SO}_{4}$. KOVALEN: Jurnal Riset Kimia, 5(3): $\quad$ 263-270. https://doi.org/10.22487/kovalen.2019.v5.i 3.12662

Risnoyatiningsih, S. (2010). Biodiesel From Avocado Seeds By Transesterification Process. Jurnal Teknik Kimia, 5(1): 345351.

https://doi.org/10.33005/jurnal_tekkim.v5i 1.136

Shiu, P.-J., Gunawan, S., Hsieh, W.-H., Kasim, N. S., \& Ju, Y.-H. (2010). Biodiesel production from rice bran by a two-step insitu process. Bioresource Technology, 101(3): $\quad$ 984-989. https://doi.org/10.1016/j.biortech.2009.09. 011

Witjonarko, R. D. E., \& Haryono, E. (2017). Kajian Eksperimental Emisi Gas Buang Two Stroke Marine Diesel Engine Berbahan Bakar Campuran Minyak Solar (Hsd) dan Biodiesel Minyak Jelantah pada Beban Simulator Full Load. Jurnal Inovtek Polbeng, $\quad 7(2)$ : 84-97. https://doi.org/10.35314/ip.v7i2.210

Yuliani, F., Primasari, M., Rachmaniah, \& Rachimoellah, M. (2008). Pengaruh Katalis Asam $\left(\mathrm{H}_{2} \mathrm{SO}_{4}\right)$ dan Suhu Reaksi pada Reaksi Esterifikasi Minyak Biji Karet. Jurnal Teknik Kimia, 3(1): 171-177. https://doi.org/10.33005/jurnal_tekkim.v3i 1.95

Zuhrotun, A. (2007). Aktivitas Anti Diabetes Ekstrak Etanol Biji Buah Alpukat (Persea americana Mill.) Bentuk Bulat [Skripsi]. Fakultas Farmasi Universitas Padjadjaran, Jatinangor. 